\title{
Correction to: Changes in the bee fauna of a German botanical garden between 1997 and 2017, attributable to climate warming, not other parameters
}

\author{
Michaela M. Hofmann ${ }^{1} \cdot$ Andreas Fleischmann ${ }^{2}\left[\right.$. Susanne S. Renner ${ }^{1}(\mathbb{C}$
}

Published online: 12 July 2018

๑) Springer-Verlag GmbH Germany, part of Springer Nature 2018

\section{Correction to: Oecologia (2018) 187:701-706 \\ https://doi.org/10.1007/s00442-018-4110-x}

Unfortunately, the electronic supplementary material was not included in the original publication and the new version is provided here.

The original article can be found online at https://doi.org/10.1007/ s00442-018-4110-x.

Electronic supplementary material The online version of this article (https://doi.org/10.1007/s00442-018-4222-3) contains supplementary material, which is available to authorized users.

Michaela M. Hofmann michaelahofmann181@gmx.de

$\triangle$ Susanne S. Renner renner@1mu.de

1 Systematic Botany and Mycology, University of Munich (LMU), Menzinger Straße 67, 80638 Munich, Germany

2 Botanische Staatssammlung München, Menzinger Straße 67, 80638 Munich, Germany 